\title{
Integrated Reporting in Business Communication: On the Example of Polish Listed Companies
}

\author{
Ryszard Kamiński \\ Adam Mickiewicz University, Poznań, Poland
}

\begin{abstract}
This work focuses on integrated reporting as an element of companies' communication with the external environment. It shows the place and role of integrated reporting in system of communication with various stakeholders and with investors in particular. It also proposes that integrated reporting is a concise communication tool depicting how an organization's strategy, governance, performance, and prospects lead to the creation of value over the short, medium, and long term. This means an integrated representation of a company's performance in terms of financial and other value relevant information. Thus, integrated reporting goes beyond the traditionally understood business financial reporting. The main aim of this paper is to explain the concept of integrated reporting and to identify the role and place of this reporting type in the system of corporate communication. An additional aim is to show the development of integrated reporting in Poland which is a relatively new EU member as well as emerging market. In conclusion, the considerations stated that the report integrated - as a report integrating financial and non-financial content, covering both past and future (which facilitates decision making) — can effectively satisfy the information needs of investors. In Poland, unfortunately, integrated reporting is not widely used. A company which produces integrated reports is based on different standards. This hampers the comparability of these reports and thus reduces their use by stakeholders. In consequence, the information needs of stakeholders are not satisfactorily addressed.
\end{abstract}

Keywords: integrated reporting, financial statement, stakeholders, business communication

\section{Introduction}

Contemporary enterprises have to operate and perform in a complex and increasingly sophisticated network of connections with various business entities from within their environment. This means that they also have to cope with and adapt to the changes in the system of their financial reporting, which is a primary means of communication between companies and their business environment. A characteristic phenomenon is deepening mutual interactions between businesses and their economic, social, and natural environment. This caused a change in the thinking about a business communication system based on corporate reporting. There are expectations that the reporting models that will be developed in the near future will be capable of meeting the information needs signaled by the internal and external stakeholders of enterprises operating in modern conditions. The response to the new needs of stakeholders and investors in particular is a process in which traditional reporting models have evolved and the emergence of reports containing financial and non-financial

Ryszard Kamiński, Ph.D., professor, Faculty of Law and Administration, Adam Mickiewicz University, Poznań, Poland.

Correspondence concerning this article should be addressed to Ryszard Kamiński, Adam Mickiewicz University, ul. Św. Marcin 90, PL 61-809 Poznań, Poland. 
issues called integrated reports. This process was the ultimate inspiration of this paper.

The main aim of this paper is to explain the concept of integrated reporting and to identify the role and place of this reporting type in the system of corporate communication. The objectives will be achieved through:

- presentation of the concept of integrated reporting;

- presentation of the main characteristics of different forms and models of integrated reporting;

- an analysis of the circumstances and conditions (legal, environmental, and organisational) that shape the quality of integrated reporting.

The work depicts the state of integrated reporting in Poland, a relatively new EU member state and an emerging market. During the preparation of the article, relevant literature and legally binding acts and regulations in Poland, the European Union, as well as legal provisions of non-obligatory character have been used. To assess the importance of integrated reporting in Poland, the annual reports of the 30 largest companies listed on the Warsaw stock exchange have been analyzed.

\section{The Framework for Integrated Reporting}

Shaping an effective system of reporting achievements by businesses requires identification of the information needs of their stakeholders. The results of the research into the information needs of stakeholders indicate that the most important group of stakeholders who are primarily investors expect greater clarity and readability of financial data, explanations of presented results (including sales), as well as a sufficiently high quality of the presented data (Dziawgo, 2011). ${ }^{1}$

Investors, in addition to the data contained in the financial statements, also expect information on the current market situation, competition, planned investments, explanations of the causes and potential consequences of events, and report about adverse events. What is also very important for investors is information about the future, including, among others, long-range forecasts for the industry (to facilitate comparison), the adopted strategy, and the implemented risk management system.

Another important group of stakeholders, stock analysts, in the capacity of investors, expect information about the future (forecasting and strategic objectives). However, they also expect many other details concerning, e.g.:

- sales and profitability (divided into industry, segments, and geographical areas);

- factors that directly affect the profit or loss (e.g., the prices of raw materials and exposure to foreign exchange risk).

This group of stakeholders also expect reliable comments of quarterly reports prepared by the boards of directors of companies.

As can be seen, investors as well as analysts are interested in a handful of different items of information and other details not included in the financial statements, but which concern to key factors influencing the activities and results of the companies. These details are largely ex ante.

Currently, the most widely used way to respond to the information needs of investors is an annual report that includes:

- letters to shareholders (i.e., a letter from the Chairman of the Supervisory Boards and letter from the

\footnotetext{
1 A study to determine the stakeholders' needs in Poland was conducted in 2009 by Dziawgo. She researched listed companies (36 entities), individual investors (416 persons), and financial analysts (10 people).
} 
President of the Management Board);

- report on the company's business activity (including the vision, strategy, market characteristics, shareholding structure, and principles upon which a company is managed and organised, an analysis of its business achievements and plans for the future);

- risk report (informing on risk factors and risk measurement, risk management policy, and internal audit system);

- financial report (describing the company's accounting policy and containing its financial statements);

- opinion of the auditor who has examined the company's financial statements.

Taking into account the information needs of investors - more and more companies voluntarily disclose additional information on the economy and management, such as the strategy, risk, value creation process, prospects for development, corporate governance, corporate social responsibility, sustainable development, intellectual capital, etc.

The released information relates to different areas of a company and there are often no clear relationships among these areas. In practice, the most frequent situation is that a number of reports are prepared separately and each refers to a certain problem, each different from one another, but which still can overlap. Therefore, these reports are only partially able to meet the information requirements of stakeholders. Several different business reports, indeed, present the activities of corporations in different sections, but information that they contain is incomplete and inconsistent. Because of the lack of a clear picture of their relationship, the understanding of the company's situation is overly complicated to grasp and the information is difficult to assess. Without more complete and comprehensive information, stakeholders are not in a position of effective decision making.

It is believed that integrated reporting is a remedy for this type of difficulty. It is assumed that an integrated report should take into account all aspects of the enterprise and put them in one coherent document that consolidates all the important information. Integrated reporting combines the most important elements of information previously presented in separate documents (the financial statements, the management report, the report on corporate governance, and the sustainability report) into one coherent whole.

Integrated reporting means a holistic approach enabling stakeholders to understand how the organization operates. Integrated reporting reveals the relationship between financial and non-financial aspects of the organization's activities and their results. Due to the enormous cultural, organizational, and industrial diversity of companies, each of these may take responsibility for its impact on the society and the environment in a different way and to a different extent (Fijałkowska \& Sobczyk, 2013).

It is postulated, however, that the integration of reports is not just a combination of several documents into one, but it is a creation of a qualitatively new report. In an integrated report, the link among the most important areas of the enterprise will be shown. The literature emphasizes the need to disclose the relationship among the strategy of the company, its management, financial results achieved, and the socio-economic and environmental determinants of its activities (International Integrated Reporting Council [IIRC], 2011).

It is assumed that an integrated report is to be a concise and clear presentation of the most important information, which means that placing irrelevant information for the reader's report, which makes it difficult to analyze should be avoided or simply given up. It is postulated, however, that this type of report should contain a properly-rich content to allow decision making, which does not mean having to increase the detail information. In contrast, a greater emphasis should be placed on the information concerning the strategy, 
business model, organizational culture, dialogue with stakeholders, collaboration with local communities, care for the environment, the existing risks, and the process of creation of value in order to obtain a comprehensive and fair view of the company (Adams \& Simnett, 2011; King, 2010). The information contained in the integrated report should be retrospective but also prospective. It is assumed that the main addressees of the integrated report are investors. However, the needs of other stakeholders cannot be ignored (KPMG, 2011). In the opinion of some experts, the stressing of the issues that are of interest to other stakeholders may also be valuable for investors. This is confirmed by the statement of DeSimone, Director of Programs Social Investment Forum:

Discussions surrounding integrated reporting have surfaced the viewpoint that sustainability reporting efforts to date have been too stakeholder focused and, therefore, do not serve any one of the stakeholders, including investors, very well. Therefore, some argue that investor supremacy should be the order of the day for developing a new framework. As an industry organization serving investors, we caution others coming to the ESG reporting table that the information that other stakeholders, including workers, consumers and community members, have been asking for is not only quite valuable to them, but is of very high worth to investors, too. (DeSimone, 2010, p. 129)

The literature points to three main types of benefits of introducing integrated reporting: firstly, the advantages of an internal nature, i.e., the board's decisions about the allocation of resources are better, and the involvement of shareholders and other stakeholders greater; secondly, there are benefits of an external nature, obtained primarily by major investors, whose information needs are met in a better way (especially in the subject of ESG); and thirdly, there are benefits arising from the reduced regulatory risk which increases, as a result of the introduction of new regulations by the government and other organizations (e.g., the stock exchange) (Eccles \& Saltzman, 2011).

\section{The Models of Integrated Reporting}

Integrated report is not standardized. However, for several years, various organizations formulate guidelines on this issue. These include IIRC and the Global Reporting Initiative (GRI).

The objective of the working group of the IIRC is to develop an "integrated reporting framework" that will:

(1) support the information needs of long-term investors, by showing the broader and longer-term consequences of decision-making;

(2) reflect the interconnections between environmental, social, governance, and financial factors in decisions that affect long-term performance and conditions, making clear the link between sustainability and economic value;

(3) provide the necessary framework for environmental and social factors to be taken into account systematically in reporting and decision-making;

(4) rebalance performance metrics away from an undue emphasis on short-term financial performance;

(5) bring reporting closer to the information used by management to run the business on a day-to-day basis.

The integrated reporting concept elaborated in 2011 by the IIRC entitled Towards Integrated Reporting Communicating Value in the 21st Century (IIRC, 2011) postulated that the reports should be:

- targeted strategic;

- focused on the future; 
- take into account the expectations and opinions of stakeholders;

- concise, accurate, and pointed to the importance of information;

- increase availability of information.

It is further assumed that individual parts of the report should be:

- an overview of the organization and its business model;

- presentation of the context of the company's activities;

- identification and assessment of risks and opportunities for business continuity;

- indication of the company's strategic goals and ways to achieve them;

- a description of corporate governance and the wage system;

- analysis of the ability to make a profit;

- show the prospects for the future.

In the concept, IIRC is assumed that the integrated reporting can improve the quality of reporting information by:

- showing a clear connection between the factors inside and outside the company and the impact of the company to other entities in the supply chain;

- better identification of opportunities and threats both by the entity preparing the report, as well as recipients of information;

- presenting broader and long-term consequences of the decisions taken by the reporting entity;

- providing information that is at a time used in the management of the entity;

- presenting a wide range of factors determining the success of the organization (Eccles \& Armbrester, 2011).

It is assumed that the result of such reporting will be:

- better meeting of the information needs of investors;

- a higher level of confidence of key stakeholders, which may result from greater transparency, as well as with their increased engagement in the process of reporting;

- smarter decisions about the allocation of resources, reduce costs;

- easier access to capital and its lower cost;

- efficient allocation of capital.

Non-financial data reporting standards developed by the GRI relate primarily to issues of sustainable development. This organization has developed principles and indicators that companies can use to measure and disclose their results obtained in the economic, environmental, and social areas. GRI standards defined indicators:

- on issues of corporate social responsibility;

- sectoral indicators relating to individual industries and services (e.g., mining and metallurgy, energy, food industry, construction, and financial services); this approach gives investors a new opportunity to compare companies from different industries (GRI, 2014).

The indicators proposed by the GRI have been included thematically into the distinguished indicators for the economy, the environment, those responsible for products and services (their impact on health and safety), employment, human rights, society, and the risk of corruption.

For the first time, the integrated reporting obligation was introduced in 2010 in South Africa. This regulation is called soft law, according to the principle "comply or explain". In practice, the company should make a report integrated and if it fails to do so, it must explain the reasons for the decision. The creators of the 
regulations introduced in South Africa recognized integrated reporting as an important step towards building a sustainable business while respecting the requirements of local communities and the environment. The authors also expressed the hope that the practice of South African companies will be spread all over the world (Eccles \& Saltzman, 2011).

Besides the South Africa, the highest degree of integrated reporting is practiced in Brazil, Germany, Sweden, and the United Kingdom. Consequently, companies from these countries are recommended to continue to exercise leadership in order to help create a more sustainable global society (Eccles, Ioannou, \& Serafeim, 2011). In most countries, integrated reporting is voluntary. Frequently such reporting is prepared by companies listed on stock exchanges. These companies include in its annual reports not only financial information but also non-financial information. However, they do not do that in a uniform manner. Relatively few companies carry out a planned and comprehensive policy to increase transparency, using extensive voluntary disclosures that are not only in the form of brochures and advertisement.

\section{Integrated Reporting in the European Union}

The results of the interviews conducted for the European Commission have shown that many readers expect sustainability reports to be integrated with the financial statements. In 2011, the European Commission undertook measures aimed to support entrepreneurship and social responsibility economy. The European Commission has proposed amendments to the European accounting legislation intended to enforce an obligation on large companies to provide additional information on social and environmental matters. These companies would need to disclose information on policies, risks, and results as regards environmental matters, social, and employee-related aspects, respect for human rights, anti-corruption and bribery issues, and diversity on the boards of directors.

According to the European Commission's fourth and seventh directives, it did not provide sufficient transparency of financial reporting or comparability of the EU member states; at the same time, due to their complexity, these directives affected the increase in administrative obligations of companies as the company experienced a particularly severe in the small- and medium-sized enterprises sector. The effect was a new law on accounting-Directive of the European Parliament and of the Council 2013/34/EC of 26 June 2013 on the annual financial statements, consolidated financial statements, and related reports of certain types of undertakings, amending Directive 2006/43/EC of the European Parliament and of the Council and repealing Council Directives 78/660/EEC and 83/349/EEC (Official Journal, 2006).

Directive 2013/34/EU refers to companies whose owners' responsibility is limited and therefore it includes joint-stock companies, public limited companies, limited liability companies, limited joint-stock, partnerships, and limited partnerships and companies with a similar legal form. The directive also applies to credit institutions and insurance companies. The directive does not apply to non-commercial entities. Entities that are subject to regulation by the directive are divided according to the criterion scale to large-, medium-, small-, and micro-sized enterprises.

The main objective of the new directive is to harmonise financial reporting principles and thus increase the clarity and comparability of financial statements. It is assumed that it will improve the functioning of the market and improve the protection of the interests of users of financial statements by providing them with the necessary information.

Directive 2013/34/EU provides for disclosure of information on environmental issues, social, and 
employment issues, including the protection of human rights, anti-fraud and corruption, respecting the principle of diversity management. The disclosure will need to include a description of the policy pursued by the company related to these matters, the results of these policies and the risks related to these matters, and how the company manages those risks.

Directive 2013/34/EU provides for the obligation of reporting non-financial information related to of corporate social responsibility by large public interest companies, having more than 500 employees, in the form chosen by the company, i.e., either in the annual financial report or in a separate report. It is predicted that improvement in business transparency and performance on social and environmental can occur in 18,000 businesses across the EU.

The directive gives companies significant flexibility to disclose relevant information in the way that they consider most useful, also or in a separate report. Companies may use international, European, or national guidelines which they consider appropriate. This directive does not require companies to comply with integrated reporting. The commission monitors the evolution of the integrated reporting concept, and, in particular, the work of the IIRC (Retrieved from http://www.iasplus.com/en/news/2013/01).

Commenting on the European Commission's proposals Druckman, Chief Executive Officer of the IIRC (IIRC), said:

The next step needs to be the integration of information that is material to value creation into the strategic decision-making and reporting processes of the business. (...) The Commission's proposals are an intelligent and logical milestone on the continuing journey towards integrated reporting as part of the evolution in corporate reporting globally. The production by businesses of non-financial information is the essential first step in equipping providers of financial capital with the data they need to make efficient and effective capital allocation decisions. (Druckman, 2013, p. 1)

\section{Integrated Reports in Poland}

In Poland, companies are required to disclose many details in financial statements. This report is regulated by the Accounting Act and Ordinances of the Minister of Finance. Under the accounting act, companies are required to include a management report in their annual reports (Retrieved from http://isap.sejm.gov.pl/DetailsServlet?id=WDU19941210591). Pursuant to article 49 of the act, a management report should comprise information on the state of affairs regarding the assets and financial condition of an undertaking and the evaluation of its performance. It should also identify the risk factors and describe the potential threats, and, in particular, provide information on:

(a) events affecting the operations of an undertaking, which occurred during the accounting year, before the date of approval of the financial statements;

(b) the undertaking's expansion projects;

(c) its major achievements in research and development;

(d) the branches that are part of the undertaking;

(e) the current and projected financial condition;

(f) the acquisition of the undertaking's own shares (treasury shares), i.e., the undertaking's shares bought back from the market, the purpose of their acquisition, their number, and the nominal (face) value of the shares, indicating which part of the initial capital they represent, as well as the price at which they were acquired, compared with the selling price of those shares; 
(g) financial instruments in respect of:

- risk: credit, change in price, material disturbances in cash flow, or loss of liquidity to which an undertaking is exposed;

- objectives and risk management methods adopted by an undertaking, including hedging methods for certain transactions to which hedging accounting is applicable;

(h) the application of the principles of corporate governance for entities whose securities are admitted to trading on a regulated market of the European economic area.

A management report should also include-insofar as it is material for the assessment of a given undertaking - environmental and employment information on the entity, its financial and non-financial ratios as well as additional explanation of the amounts disclosed in the financial statements.

There is no binding legal regulation regarding the format in which the above data should be presented in the management report. Consequently, it is up to an undertaking to decide what form or format the report should take. What is important though is that an undertaking follows the principle of material impact that certain business transactions or occurrences may have on the assessment of its assets, financial condition, financial result, or profitability. In practice, what is included in the management report is also determined by and dependent on what an undertaking is willing to disclose and what it may want to protect as commercial or business secrets. The latter, however, may only be justified if a disclosure of some information might work to the detriment of an undertaking publishing a management report. This report should be based on:

- documented data presented in the financial statements and prepared for the relevant accounting period;

- projections and assumptions that should be adequate for the realistic possibilities of an undertaking and justified by decisions made by its management.

A management report must be communicative and provide information on the economic (business) situation and financial condition of the undertaking as well as its growth and expansion prospects. The internal characteristics of an undertaking included in a management report should be presented in the context of the existing external conditions. The management's opinion of the business and the condition of the undertaking in a given accounting year should be included in such a report as well.

In the case of Polish companies that are issuers of shares and securities, the disclosure of reporting information is further regulated in the Ordinance of the Minister of Finance dated on 19 February, 2009 on current and periodic information disclosed by issuers of securities and the conditions of recognizing this information as equivalent to the information required by the laws of non-EU member states (Retrieved from http://isap.sejm. gov.pl/DetailsServlet?id=WDU20090330259). The said ordinance sets out the type, scope, form, time table, and frequency of reporting of the current and periodic information by issuers of securities. As provided for in $\S 82$ of the ordinance, issuers of securities are required to prepare periodic reports, including quarterly reports, semi-annual reports, and annual reports. The periodic reports prepared for control purposes are made available to the public and to stock market investors, in particular. They are published on the websites of the issuers.

The Ordinance of the Minister of Finance of 19 February, 2009 contains a detailed list of information which should be included in management reports. The report should list significant events that took place in the current period and an explanation of the differences between the financial results disclosed in the annual report and previously published results forecasts. The ordinance requires that the report contains the characteristics of internal and external factors relevant to the development of the company and the prospects for its development. 
A separate section of the report must be a statement on corporate governance.

Since it is possible that the information provided in accordance with the requirements laid down in the legislative acts referred to above may not show the full picture of the company's business, additional information (or notes to financial statements), referred to as voluntary disclosures, may be disseminated. Using that option, companies more and more frequently provide additional information about themselves in order to enhance communication with stakeholders and to enable the existing and potential investors to make more accurate assessment of their activities. It is believed that increasing the amount of voluntary disclosures enhances the company's corporate image and goodwill, which results in increased investor confidence, ultimately resulting in higher valuation of the companies themselves.

Because of this, many companies draw up an additional annual report, sometimes called a "marketing report", which is a presentation of the conditions of the company, together with the statement of the main results and forecasts. The report is drawn up in the form of more affordable than in the supervisor's report (for financial supervision commission ${ }^{2}$ ). It is addressed to stakeholders company, especially to investors, so that they can better understand the specifics of the organization. In the opinion of experts, annual "marketing reports" is the media, which is closest to the idea of integrated reporting. They believe that the adaptation of the content of these reports, the requirements contained in the IIRF, would improve corporate communications with investors and other stakeholders.

In Poland, an increasingly more space in reports is devoted to the presentation of non-financial information; however, here again companies do not do so in a uniform manner. Below are the results of a study which included 30 largest companies listed on the stock exchange in Warsaw (they are a collection of companies accounted for calculating the WIG index 30). ${ }^{3}$ These companies represent a variety of sectors of economy such as:

- industry (raw materials, fuel, chemical, metal, and food)—10 companies;

- energy (generation, transmission, and sale of energy) - four companies;

- construction-one company;

- media and information services-four companies;

- trade - three companies;

- banking - seven companies;

- insurances-one company.

All the investigated companies draw up an annual report required by the provisions of the accounting act and reports required by the Regulation of the Minister of Finance. However, only a portion of the surveyed companies prepare reports that aspire to integrated reports or sustainability reports. The number of these companies is 13 (i.e., 43\%). On this count, eight companies represent the industry, two trade, one building, one energy, and one banking. In their reporting, most of these companies have devoted most attention (except for financial issues) to issues of corporate social responsibility. These reports have been usually prepared in accordance with the guidelines of the GRI (eight cases). However, they have also been prepared with the use of guidelines Global Compact, ISO 26000, OECD Guidance on social responsibility, and the International

\footnotetext{
${ }^{2}$ Financial Supervision Authority (FSA) is central state administration body supervising the financial market in Poland. FSA was established under the act of 21 July, 2006 on the supervision of financial market. Supervision over the activities of the commission is exercised by the Prime Minister.

${ }^{3}$ Currently on the stock exchange in Warsaw is 472 listed companies (May 2015).
} 
Council on mining and metals. Sometimes, the methodology of preparing the report was based on guidance from various sources. It is clear that the use of different methodologies in the preparation of annual reports makes it difficult to compare among companies.

Some of these reports are in full compliance with the requirements of the integrated report (e.g., Lotos SA, Zakłady Azotowe Puławy). However, most of these reports do not adequately show a link among the issues presented. Moreover, they were too long (200-300 pages), making it difficult for stakeholders to understand the nature of the business in which these companies were engaged.

The remaining companies from the study group have been found to prepare annual reports only on the basis of the principles set out in the accounting act and the regulations the Minister of Finance. The contents of these reports comply to the requirements of the legislation, but the most common is that their annual reports are only collections of separate thematic reports. The basic weakness of these reports is that much information is disclosed without any context, key performance measures are not linked to the strategy, and there is no relationship shown between the financial and non-financial information. This considerably reduces the value of these reports as a decision-making basis for stakeholders.

\section{Conclusions}

Stakeholders expect speedy and increasingly faster and more detailed information on the key areas of the company, including information about the future. Thus, apart from the classical understanding of financial reporting, reports and projections for future non-financial areas are also important. The characteristics of an integrated report presented above seem to strongly justify formulation of a thesis that an adequate answer to the information needs of stakeholders is a report that integrates the financial and non-financial contents. The rules governing the preparation of an integrated report and its contents fit well into the expectations of stakeholders' information. Much of its content concerns the future; as such it helps stakeholders to formulate bases for their decisions. An integrated report can be seen as an important part of a modern model of shaping relations between a company and its stakeholders. In the future, an integrated report will probably become a very important medium of communication between companies and their business environment. Even today, it frequently replaces reports that are incompatible with each other (in terms of content and structure) and other reports (attached to the financial statements). Yet - as can be judged - an integrated report does not have to replace the financial statements in the traditional sense.

Implementation of integrated reporting is a major challenge for both theoretical and practical spheres. First of all, there is a need to modify the existing reporting process towards the identification and disclosure of relationships of different areas of the company activities and at the same time, the necessity of joining together the ex post information and ex ante information. This will probably be associated with the need to develop new information systems. It is obvious that preparation of company's integrated report generates additional costs. Therefore, its implementation must provide added value for both stakeholders and companies, otherwise it may become just an unnecessary burden, decreasing the efficiency of the latter.

Integrated reporting in Poland is at the early stage of development. The need for disclosure of financial and non-financial is the result of the legal requirements - under Polish and the European Union law. This obligation is imposed on large-size companies, including companies listed on the stock exchange. Therefore, it is not surprising that these companies were first which began to prepare reports that integrate financial and non-financial information, past and for the future information. Due to the fact that there is no one set of 
universally accepted standards for integrated reporting applicable globally-reports prepared by Polish companies are based on different international standards. Still, as it can be easily seen that the most commonly used are standards developed by the GRI. There is currently a lively discussion going on in Poland, concerning integration of reporting information. This is because shareholders have started to notice the shortcomings of annual reports drawn up by companies in compliance with the applicable law. Probably in the future, it will be necessary to develop (or select one from the already existing ones) one common standard for integrated reporting applicable to all or selected entities (e.g., public companies). These changes in the reporting system in Poland will be a response to the proposals of change which is the accounting policy under the EU laws.

\section{References}

Adams, S., \& Simnett, R. (2011). Integrated reporting: An opportunity for Australia's not-for-profit sector. Australian Accounting Review, 21(3), 293.

Deloitte, IASPlus. (2013). European Commission proposes ESG disclosure for large companies. Retrieved from http://www.iasplus.com/en/news/2013/01

DeSimone, P. (2010). An SRI perspective on integrated reporting. In R. G. Eccles, B. T. Cheng, and D. Saltzman (Eds.), The landscape of integrated reporting reflections and next steps edited (The President and Fellows of Harvard College Cambridge, Massachusetts).

Druckman, P. (2015). European Commission proposals: An important milestone on the journey towards integrated reporting. Retrieved from http://www.theiirc. org/2013/04/30/european-commission-proposals-an-important-mileston-on-the-journey-towards-integrated- reporting/

Dziawgo, D. (2011). "Nowe" sprawozdanie finansowe—głos w dyskusji ("The new" financial statements-A voice in the discussion). Zeszyty Teoretyczne Rachunkowości, 62(118), 88-95.

Dziennik Ustaw. (1994). Accounting act of 1994 September 29 (No. 121. Item 591). Retrieved from http://isap.sejm.gov.p1/DetailsServlet?id=WDU19941210591

Dziennik Ustaw. (2009). Ordinance of the Minister of Finance dated 2009 February 19 on current and periodic information disclosed by issuers of securities and the conditions of recognizing this information as equivalent to the information required by the laws of non-EU member states (No. 3. Item 259). Retrieved from http://isap.sejm.gov.pl/DetailsServlet? id=WDU20090330259

Eccles, R. G., \& Armbrester, K. (2011). Integrated reporting on the cloud. IESE Business School (Issue 8, first quarter). Retrieved from www.ieseinsight.com/review

Eccles, R. G., \& Saltzman, D. (2011). Achieving sustainability through integrated reporting. Stanford Social Innovation Review. Retrieved from http://people.hbs.edu/rec D - cles/2011SU_Features_EcclesSaltzman.pdf

Eccles, R. G., Ioannou, I., \& Serafeim, G. (2011). The impact of a corporate culture of sustainability on corporate behavior and performance (Working paper 12-035, Harvard Business School).

Fijałkowska, J., \& Sobczyk, M. (2013). Integrated reporting as a cross-border communication tool for business-A fad or a sign of times? Journal of Intercultural Management, 5(4), 36.

Global Reporting Initiative. (2014). G4 sustainability reporting guidelines, reporting principles and standard disclosures. Retrieved

from https://www.globalreporting.org/resourcelibrary/GRIG4-Part1-Reporting-Principles-and-Standard-Disclosures.pdf

International Integrated Reporting Council [IIRC]. (2011). Towards integrated reporting. Communicating value in the 21st century. Retrieved from http://theiirc.org/wp-content/uploads/2011/09/IR-Discussion-Paper-2011_spreads.pdf

King, M. (2010). Formation of the international integrated reporting committee (IIRC). Retrieved from http://www.ey.com/Publication/vwLUAssets/EY-Integrated-reporting/\$FILE/EY-Integrated-reporting.pdf

KPMG. (2011). Integrated reporting, performance insight through better business reporting. Retrieved from http://www.kpmg.com/AU/en/IssuesAndInsights/ArticlesPublications/Better-Business-Reporting/

Official Journal L 157. (2006). Directive 2006/43/EC of the European Parliament and of the Council of 17 May 2006 on statutory audits of annual accounts and consolidated accounts, amending Council Directives 78/660/EEC and 83/349/EEC and repealing Council Directive $\quad 84 / 253 / E E C$ Retrieved from http://eur-lex.europa.eu/legal-content/EN/TXT/?uri=celex:32006L0043 